\title{
Sectoral breakdown of total factor productivity in Chile, $1996-2010^{1}$
}

\author{
Patricio Aroca ${ }^{2}$ and Nicolás Garrido ${ }^{3}$
}

\begin{abstract}
This article decomposes total factor productivity (TFP) by economic sector, using data from the Chilean economy's input-output matrices for 1996, 2003 and 2010. The analysis focuses on the effects of changes in three areas: sectoral demand; the production mix and cross-sectoral transactions; and technological change. It finds that the latter two are the key drivers of productivity variations in the period analysed. Manufacturing industry; electricity, gas and water; and financial intermediation and business services have generated increases in the economy's overall productivity, while the personal services sector may be acting as a constraint on growth. The article qualifies and contextualizes these conclusions.
\end{abstract}

\section{Keywords}

Productivity, measurement, input-output analysis, factor analysis, Chile

\section{JEL classification}

$$
\text { 041, 047, C67 }
$$

\section{Authors}

Patricio Aroca is a tenured professor at the School of Business of Adolfo Ibáñez University, Chile. patricio.aroca@uai.cl

Nicolás Garrido is associate professor in the Economics Department at Diego Portales University, Chile. nicolas.garrido@udp.cl

The authors are grateful for comments made by those attending presentations of preliminary versions of this article at seminars held at the Adolfo Ibáñez University and at the seminars of Núcleo Intelis, Millennium Scientific Initiative.

2 The author is grateful for financing received from the Fund for the Promotion of Scientific and Technological Development, (FONDEF), as part of the project "Measurement of impact and spillovers from regional projects in Chile" (Code CA13/1006).

3 The author is grateful for financing received from the National Fund for Scientific and Technological Development (FONDECYT), as part of the project "Analysis of regional and sectoral productivity and its influence on the aggregate economy" (No. 1140131). 


\section{Introduction}

Two key assertions are made in the studies by Prescott (1998) and Easterly and Levine (2002). In the first, of an empirical nature, the authors argue that total factor productivity (TFP) (Solow, 1957) is the best construct for differentiating growth rates and gross domestic product (GDP) in different countries. In a second, more theoretical, comment, they note the lack of consensus on the concept of TFP, which makes it impossible to define and measure unambiguously. These two claims have spawned numerous debates and much research in academic circles. The present study contributes to those debates by proposing a new, innovative, way of measuring TFP in the Chilean economy, in which input-output tables are used to break the economy-wide TFP down into contributions made by 12 economic sectors.

The study of TFP in Chile spans different periods and focuses on the macro-, meso- and microeconomic levels, depending on the information available. The greater availability of aggregate information allows more research on TFP at the macroeconomic level. Fuentes, Larraín and SchmidtHebbel (2006) show that productivity increases accounted for more than $60 \%$ of economic growth in periods of high and moderate expansion (1990-1997 and 1998-2005, respectively). ${ }^{4}$ These authors argue that TFP is related to structural and cyclical components of the economy: whereas structural factors, including macroeconomic stability, played an important role in pre-1990s periods, the situation has been reversed in the last 20 years when TFP fluctuations have mainly been caused by cyclical effects such as the terms of trade (the price of copper) and the devaluation of the real exchange rate. Chumacero and Fuentes (2006) argue that an exogenous growth model is the best way of interpreting economic data in which there is a steady-state TFP trend and temporary increases arising from improvements in capital quality (calculated by comparing the prices of capital goods and consumer goods); an improvement in the terms of trade; and a reduction in distortions in official measurements, such as government spending. The authors note that when such increases are due to current policies, the change may be long-term, while transitory changes give rise to productivity fluctuations.

Progressively, as the productivity gains from macroeconomic stability began to dwindle, research turned to considering microeconomic influences on TFP and how they complement institutional stability. Studies found links between firms and productivity based on the abundant data from the Annual National Industrial Survey (ENIA). Pavcnik (2002) found evidence that trade liberalization had enhanced enterprise productivity. Several hypotheses to explain the transmission channels of these improvements were also formulated, as follows: (i) greater specialization; (ii) the expansion of potential markets, to take advantage of economies of scale; (iii) dissemination of technological innovations and good management practices; and (iv) reduction of anti-competitive practices at the local level. Bergoeing, Hernando and Repetto (2005) note that TFP growth in firms reflected improvements made within them, rather than the factor relocation that might have been induced by a Schumpeterian process of enterprise "death and birth". The structure of the labour market and its effect on productivity were studied by Álvarez and Fuentes (2009), who argue that the rise in minimum wages may have undermined TFP in recent years, and mainly affected firms with a larger proportion of low-skilled workers.

The meso-economy ${ }^{5}$ of the country and its relation to productivity are topics that received later attention, specifically in the studies by Álvarez and Fuentes (2004), Vergara and Rivero (2006)

4 This conclusion is reached with the method used by Fuentes, Larraín and Schmidt-Hebbel (2006), whereby the TFP measurement is estimated from a capital stock that is calculated adjusting for energy consumption and employment through the wage rate and hours worked. The results are not very different when the other measures are used.

5 The term "meso-economy" is used to describe entities that are clearly identifiable, such as the economic sectors and regions of a country, but which do not directly represent the microeconomic behavior of buying and selling in markets, nor do they describe aggregate properties of the macroeconomy as a whole. 
and Fuentes (2011). The latter author shows that there was a structural break in labour productivity towards the end of the 1990s in many sectors (agriculture, fishing and forestry, mining, commerce, restaurants and hotels, and transport and communications); and that this seems to be related to the macroeconomic productivity effect of structural changes and cyclical components (Fuentes, Larraín and Schmidt-Hebbel, 2006). By decomposing the increase in labour productivity into two categories - sectoral and attributable to labour reallocation between sectors - the authors were able to calculate that over $97 \%$ of the increase was sectoral and only $3 \%$ arose from reallocation. The tradable goods sectors (mining and manufacturing) display a process of capital deepening that drove labour productivity growth, while TFP had a significant impact on labour productivity in the commerce, restaurants and hotels sectors, and in transport and communications. Álvarez and Fuentes (2004) reach a similar conclusion: the expansion of the mining; manufacturing; and agriculture, forestry, and fisheries sectors in the 1990s was a consequence of capital accumulation and TFP, while growth in the non-tradables sector in the same decade was primarily due to capital accumulation alone. Vergara and Rivero (2006) report conclusions that highlight the heterogeneous performance of tradable goods sectors. In two of these (agriculture-forestry-fishing, and the mining sector) TFP growth outpaced capital accumulation in 1996-2001, while just one sector (manufacturing industry) displays the opposite pattern. According to Fuentes (2011), the construction and financial services sectors may have had a very low TFP growth rate, ${ }^{6}$ while Vergara and Rivero (2006) report that financial services posted the second highest TFP growth in 1986-2001.

This wide diversity of results warrants three comments. First, the technical criteria and data sources used to measure the country's productivity vary greatly, even though the conceptual basis of measurement remains the decomposition of growth accounting. Second, Harberger's (1998) hypothesis that productivity increases are mushroom-like, and cost reductions may be due to "1,001 possible causes" in different sectors, with productivity increase adopting many different guises, seems to apply in the Chilean case. Third, the heterogeneity of results also suggests a relationship between microeconomic, meso-economic and macroeconomic productivity, to enable an integrated reading of the different conclusions from a broad perspective.

This article presents two new approaches to the analysis of sectoral TFP in Chile. First, the information provided by the Central Bank is organized into input-output tables for the years 1996, 2003 and 2010 and made compatible with the relevant data of the National Institute of Statistics (INE). Next, the total TFP of the economy is decomposed into sectoral contributions, the effects of demand and the effect of interaction between sectors. Intersectoral productivity is compared using the Solow growth-accounting model while taking account of the remarks made by Baumol and Wolff (1984).

The results of this research make it possible to construct a taxonomy of sectors, according to their capacity to drive the economy and variations in sectoral productivity. In this taxonomy, the leading sectors are manufacturing industry; electricity, gas and water, and financial intermediation and business services, which led TFP growth in 1996-2010. The productivity growth recorded in these sectors spread throughout the productive fabric.

In this context, the personal services sector could be holding back productivity growth in the economy overall, since its productivity declined in the period analysed, and this had a major impact throughout the production system.

Apart from this introduction, the article is organized in three sections. Section II describes the decomposition method used to analyze productivity, while section III explains the origin of the data and analyses the results of the decomposition; and section IV presents the conclusions. The article concludes with an annex giving details of the calculation methods used.

\footnotetext{
6 This suggestion is tentative because it is based on Fuentes (2011), which concludes that there was a process of capital intensification coupled with virtually zero labour-productivity growth.
} 


\section{Decomposition method}

Total factor productivity measures output growth that does not reflect an increase in the primary factors of production, namely capital and labour. Many different measurement techniques are used; and there is an abundant literature on the subject, summarized in several compendia such as Del Gatto, Liberto and Petraglia (2011), and Timmer and others (2010).

In this study, TFP was decomposed and measured using data contained in the Chilean economy's input-output tables. According to the classification of the main productivity measures developed by the Organization for Economic Cooperation and Development (OECD, 2001), the procedure used can be referred to as multifactor. The measurement used in this study is based on value-added, rather than the gross output used by the OECD measure of productivity of capital $(K)$, labour $(L)$, energy $(E)$, materials (M) and services (S), referred to in the OECD manual as KLEMS. As indicated in table 3 of the 2001 OECD manual, the difference between the two measurements is important. Nonetheless, in order to compare the results presented in this article with those reported in other studies on productivity in Chile, it was decided to base the calculations on value-added.

Input-output tables make it possible to calculate a productivity measure that can be broken down into sectoral contributions, within a consistent analytical framework, as outlined in the aforementioned OECD manual. For the sectoral decomposition of TFP, the method applied by Wolff (1984 and 1985) is used, to describe the changes in production that influenced the fall in productivity growth in the United States after World War II.

In accordance with the formal model, the following variables were defined:

$x_{t}$ : column vector of gross sectoral output in period $t$

$y_{t}$ : column vector of the final demand of each sector in period $t$

$A_{t}$ : matrix of intersectoral coefficients in period $t$

$l_{t}$ : row vector of labour coefficients in period $t$, which indicates the volume of labour needed in each unit of production

$k_{t}$ : row vector of capital coefficients in period $t$, which indicates the amount of capital needed in each unit of production

$p_{t}$ : row vector of prices in period $t$, which indicates the price of each unit produced in the different industries.

In addition, the following scalar variables were defined:

$w_{t}$ : average wage rate of all sectors in period $t$

$r_{t}$ : rate of return on the capital stock in period $t$

$Y_{t}=p_{t} y_{t}$ : gross national product at current prices in period $t$

$L_{t}=l_{t} x_{t}$ : total employment in the economy in period $t$

$K_{t}=k_{t} x_{t}$ : total capital stock in the economy in period $t$.

The application of Solow's growth accounting technique (1957), which only assumes constant returns to scale and a perfectly competitive environment, makes it possible to define total factor productivity as:

$$
\rho=\frac{d Y}{Y}-\frac{w L}{Y} \frac{d L}{L}-\frac{r K}{Y} \frac{d K}{K}
$$


If the information obtained from the input-output model is considered, the values can be expressed as follows:

$$
\rho=\frac{(p d y-w d L-r d K)}{Y}
$$

As sectoral demand can be expressed as the difference between gross output and intermediate purchases, then

$$
y=(I-A) x
$$

The change in demand can be expressed through differentiation as,

$$
d y=(I-A) d x-(d A) x
$$

Similarly, employment and capital can be differentiated as follows:

$$
\begin{gathered}
d L=l d x+(d l) x \\
d K=k d x+(d k) x
\end{gathered}
$$

If the relevant substitutions are made in equation (1),

$$
\rho=\frac{(p(I-A) d x-p(d A) x-w l d x-w(d l) x-r k d x-r(d k) x)}{Y}
$$

This expression is simplified by using the identity between the price of a good and the cost of intermediate goods and factor payments. Formally,

$$
p=p A+w l+r k
$$

or

$$
p(I-A)=w l+r k
$$

Making the relevant substitutions in equation (2), gives:

$$
\rho=\frac{-(p d A+w d l+r d k) x}{Y}
$$

In the study by Miller and Blair (2009), the productivity of a sector $j$ is defined as:

$$
\pi_{j} \equiv \frac{-\left(p d a_{. j}+w d l_{j}+r d k_{j}\right)}{p_{j}}
$$

where $a_{, j}$ to column $j$ of matrix $A$ and represents the number of units from intermediate sector $i$ needed to produce in sector $j$. Similarly, $l_{j}$ and $k_{j}$ represent the number of units of labour and capital, respectively, needed to produce one unit of sector $j$. Thus, productivity in sector $j$ increases when fewer inputs and factors are used to produce one unit at constant prices.

Under this definition, the aggregate productivity of equation (3) can be expressed as:

$$
\frac{\pi \hat{p} x}{Y}
$$

where $\pi$ is the column vector of sectoral productivity and $\hat{p}$ is the diagonalized prices vector. 
Next, applying the relation $x=(I-A)^{-1} y$ and the identity $I=\hat{p}^{-1} \hat{p}$, aggregate productivity can be expressed as

$$
\rho=\frac{\pi \hat{p}(I-A)^{-1} \hat{p}^{-1} \hat{p} y}{Y}
$$

To simplify the notation, the foregoing equation can be expressed as:

$$
\rho=\pi S \beta
$$

where $\pi$ is a row vector in which each component $j$ represents the productivity of the corresponding sector. The matrix $S=\hat{p}(I-A)^{-1} \hat{p}^{-1}$ encapsulates the economic effects of transactions between industries. Each term $s_{i, j}$ of matrix $S$ can be expressed as $s_{i, j}=\frac{l_{i, j} p_{i}}{p_{j}}$, where the technical multiplier, ${ }^{7}$ $l_{i, j}$ represents the direct and indirect increase generated in the physical production of good $i$ as a result of increasing the demand for good $j$. Consequently, $s_{i, j}$ represents the multiplier of good $i$, derived from an increase in its demand, compared to the price of good $j$. This could be summarized by saying that if, instead of considering the multiplier $l_{i, j}$, which includes both direct and indirect effects, only the direct effect of technical coefficient $a_{i, j}$ of the technical coefficient matrix $A$ were considered, the economic effects would be expressed as $\tilde{s}_{i, j}=\frac{a_{i, j} p_{i}}{p_{j}}$, where $\tilde{s}_{i, j}$ represents the cost of input $i$ relative to that of $\operatorname{good} j$.

Lastly, $\beta=\frac{\hat{p} y}{Y}$ is a row vector in which each position $j$ represents the share of sector $j$ in the final demand of the economy. This vector can also be interpreted as the preference for spending in certain sectors as revealed by the country's demand.

Taking the decomposition expressed in equation (4) and ignoring the second order effects, the change in TFP can be linearly approximated as:

$$
\Delta \rho=\pi S \Delta \beta+\pi \Delta S \beta+\Delta \pi S \beta
$$

While the first term on the right represents the change in productivity arising from the change in demand preferences, the second term refers to the change attributable to the intersectoral effects, and the third represents the intrasectoral changes.

\section{Data and results}

The calculations described in this article were made using data from the national accounts databases of the Central Bank of Chile for the years 1996, 2003 and 2010. Data from the National Institute of Statistics were also used to calculate the average hourly wage of workers in each year; and the sectoral capital stock data reported by Henríquez (2008) were also considered.

Fuentes, Larraín and Schmidt-Hebbel (2006) provide evidence that the behavior of TFP is linked to the cyclical components of the economy. Thus, to have a timeline reference, figure 1 shows the cyclical component of gross domestic product at constant prices, calculated by applying the HodrickPrescott (1981) filter $(\lambda=1,600)$. The vertical bars (years 1996, 2003 and 2010) represent the inputoutput data used in the calculation.

\footnotetext{
7 In terms of the standard Leontief notation, $L=(I-A)^{-1}$, so $l_{i, j} \in L$.
} 
From 1996 to 2003, a downswing phase, the economy grew at roughly 3.5\% per year. In the ensuing period, spanning 2003 to 2010, annual growth averaged $4.5 \%$.

Figure 1

Business cycle, 1986-2010

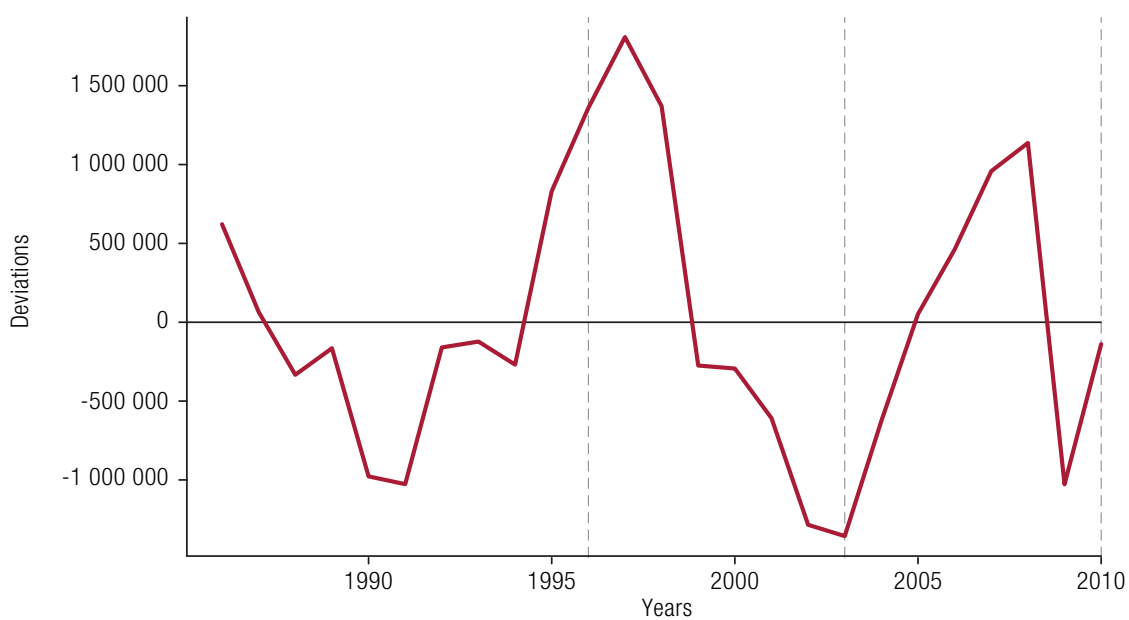

Source: Prepared by the authors, on the basis of data from the Central Bank of Chile.

Table 1 shows the increase in the sectors' gross production value (GPV) in the two periods considered, with three sectors recording average annual growth rates above 5\%: mining; electricity, gas and water; and financial intermediation and business services. In a second group (public administration; personal services; and commerce, hotels and restaurants) growth rates were modest, while a third group (fishing, transport and communications, and manufacturing) reported a sharp slowdown.

Table 1

Annual increase in gross production value (GPV)

(Percentages)

\begin{tabular}{lcc}
\hline Sector & $1996-2003$ & $2003-2010$ \\
\hline Agriculture-forestry & 3.2 & 1.6 \\
\hline Fishing & 5.5 & -2.8 \\
\hline Mining & 7.2 & 11 \\
\hline Manufacturing industry & 3.8 & 0.9 \\
\hline Electricity, gas and water & 5.3 & 9.2 \\
\hline Construction & 0.4 & 3.9 \\
\hline Commerce, hotels and restaurants & 3.3 & 3.6 \\
\hline Transport and communications & 8.9 & 1 \\
\hline Financial intermediation and business services & 7.4 & 6.1 \\
\hline Housing services & & 2.5 \\
\hline Personal services & 1.1 & 3.8 \\
\hline Public administration & 5.6 & 4.6 \\
\hline All sectors & 3.5 & 3.68 \\
\hline
\end{tabular}

Source: Prepared by the authors.

\section{Wage and labour technical coefficients}

The average wage was calculated using data from the National Institute of Statistics on the distribution of employment in the 12 sectors in 1996, 2003 and 2010 (see table 2). This information was supplemented by data from the Central Bank of Chile for the same years, which show that the average 
number of hours worked per week was approximately 46, 43.3 and 40, in those years respectively. Multiplying these figures by the number of workers in each sector makes it possible to calculate the vector, which represents the total number of hours worked per sector.

Table 2

Number of workers per sector

(Thousands)

\begin{tabular}{lrrr}
\hline Sector & \multicolumn{1}{c}{1996} & \multicolumn{1}{c}{2003} & \multicolumn{1}{c}{2010} \\
\hline Agriculture-forestry & 723.17 & 710.96 & 703.24 \\
\hline Fishing & 66.17 & 81.3 & 45.62 \\
\hline Mining & 92.37 & 79.33 & 199.17 \\
\hline Manufacturing industry & 844.89 & 822.73 & 799.31 \\
\hline Electricity, gas and water & 39.22 & 26.2 & 58.88 \\
\hline Construction & 406.21 & 461.7 & 562.5 \\
\hline Commerce, hotels and restaurants & 925.96 & 1129.12 & 1746.53 \\
\hline Transport and communications & 387.21 & 484.38 & 522.57 \\
\hline Financial intermediation and business services & 353.08 & 471.12 & 574.64 \\
\hline Housing services & 0.00 & 0.00 & 0.00 \\
\hline Personal services & 1137.82 & 1257.89 & 1497.94 \\
\hline Public administration & 204.92 & 263.79 & 391.74 \\
\hline All sectors & 5181.02 & 5788.52 & 7102.14 \\
\hline
\end{tabular}

Source: Prepared by the authors, on the basis of data from the National Institute of Statistics and the Central Bank of Chile.

a The housing services sector has no workers, because the figures for this sector represent the annual rental for use of the housing in question.

The average wage is calculated as the ratio between total wage payments and the number of hours worked:

$$
w=\frac{i^{\prime} l_{v}}{i^{\prime} l_{n}}
$$

where $i$ is a unit vector, $l_{v}$ is the vector of payments to workers in each sector, and $l_{n}$ is the vector indicating the number of hours worked in each sector.

The vector of labour technical coefficients, $l$, for each year, is calculated by dividing the number of hours worked in each sector by the gross value of sectoral output, as follows:

$$
l=\hat{x}^{-1} l_{n}
$$

where, as before, $l_{n}$ is the vector of hours worked in each sector and $x$ is the value of the gross output of each sector, expressed at constant prices.

\section{Price of capital services and capital technical coefficients}

The capital indicators were calculated on the basis of information presented in Estudios Económicos Estadísticos No. 63 of the Central Bank of Chile (Henríquez, 2008) and updated to 2010, pursuant to the criteria specified in the System of National Accounts 2008 (United Nations, 2009) and expanded in the OECD manual on measuring capital (OECD, 2009). 
In the case of the capital stock, there are major differences between data needs and availability (see table 3).

Table 3

Comparison of sectors considered for calculating capital

\begin{tabular}{ll}
\hline In this study & In Henríquez (2008) \\
\hline Agriculture-forestry & Agriculture, forestry and fishing \\
\hline Fishing & Mining \\
\hline Mining & Industry \\
\hline Manufacturing industry & Electricity, gas and water \\
\hline Electricity, gas and water & Construction \\
\hline Construction & Commerce, restaurants and hotels \\
\hline Commerce, hotels and restaurants & Transport and communications \\
\hline Transport and communications & Financial and business services \\
\hline Financial intermediation and business services & Housing services \\
\hline Housing services & Community and social services \\
\hline Personal services & \\
\hline Public administration & \\
\hline
\end{tabular}

Source: Prepared by the authors.

The capital of the agriculture, forestry and fisheries sector considered is measured in aggregate in Henríquez (2008). To distribute this between the agricultural-forestry and fishery sectors the capitaloutput ratio was assumed to be the same in both cases, so the calculation was as follows:

$$
k_{1}=k_{\text {asp }} \frac{x_{1}}{x_{1}+x_{2}} \quad k_{2}=k_{a s p} \frac{x_{2}}{x_{1}+x_{2}}
$$

where $k_{a s p}$ is the aggregate capital stock of the agriculture-forestry and fishing sectors, and $x_{1}$ and $x_{2}$ represent the gross output of the agriculture and forestry sector, on the one hand, and of the fishing sector on the other; $k_{1}$ and $k_{2}$ are the capital values calculated for each sector.

Henríquez (2008) does not provide information on the capital stock of public administration. To calculate this amount approximately, the capital-output ratio of all sectors, excluding public administration, was calculated.

$$
v=\frac{\sum_{i \neq g} k_{i}}{\sum_{i \neq g} x_{i}}
$$

Next, it was assumed that the capital-output ratio of public administration is equal to that of the government sector, which made it possible to calculate from the output of the latter:

$$
k_{g}=v \cdot x_{g}
$$

where $x_{g}$ is the gross production reported in the national accounts and $k_{g}$ is the government's estimated capital stock.

The price of capital services was determined as follows:

$$
r=p_{k}\left(r_{0}+\delta_{k}-\frac{\dot{p}_{k}}{p_{k}}\right)
$$

where $r_{0}, \delta_{k}$ and $p_{k}$, represent the interest rate (opportunity cost), rate of depreciation and the price of (or return on) capital, respectively. 
The value added of capital, as recorded by the Central Bank of Chile, can be defined as:

$$
k_{v}=r \phi k
$$

where $r$ represents the price of capital services and $\varnothing$ is the utilization factor, which indicates the amount used (including, per hour) of the available capital stock, $k$, which is the monetary expression of the capital stock available for production purposes (including, equipment, cars and properties) acquired in the past.

The capital utilization ratio is calculated using physical quantities, as indicated in the following equation:

$$
c_{k}=\frac{\rho_{k} \phi k}{\rho_{x} x}
$$

where $\rho$ is the deflator that makes it possible to relate the measures of capital $k$, gross output $x$, and $\varphi$ the rate of utilization of capital, to a base year 0 . Thus, the coefficient $c_{k}$ (a technical coefficient of production) is the physical capital needed for each unit of production.

The following equation is used to calculate the price of capital services:

$$
r=\frac{k_{v}}{\phi K}
$$

In this case, it can clearly be seen that when the result is divided by the effective capital utilization rate, $\varnothing K$, the price can be determined, because $r=\frac{k_{v}}{\phi K}=\frac{r \phi K}{\phi K}=\frac{r \phi}{\phi}$.

\section{Total factor productivity}

By applying the calculation rules set out in the annex, the matrices of the technical coefficients necessary to determine the change in TFP between the three periods were calculated from the use and production matrices, according to equation (4).

The results of this calculation are summarized in table 4, which also shows the growth-rates of value-added.

Table 4

Aggregate TFP and share growth

(Percentages)

\begin{tabular}{lccc}
\hline & $\begin{array}{c}\text { Growth of value-added } \\
(1)\end{array}$ & $\begin{array}{c}\text { Growth of TFP } \\
(2)\end{array}$ & $\begin{array}{c}\text { Share of TFP } \\
(2) /(1)\end{array}$ \\
\hline $1996-2003$ & 27.15 & 4.95 & 18.23 \\
\hline $1996-2003$ (annual) & 3.491 & 0.693 & 15.66 \\
\hline $2003-2010$ & 36.07 & 5.65 & \\
\hline $2003-2010$ (annual) & 4.498 & 0.788 & \\
\hline
\end{tabular}

Source: Prepared by the authors, on the basis of data from the National Institute of Statistics and the Central Bank of Chile.

Although TFP of 1996-2003 was lower than that of 2003-2010, its relative contribution to growth was higher in the first period, as can be seen in the last column of the table.

Table 5 sets out the results of Chile's TFP calculations as reported in other studies for the same periods. The fact that the results are so heterogeneous reflects the use of different data sources and the application of different methods. 
Table 5

Annual TFP calculated in different studies

(Percentages)

\begin{tabular}{lc}
\hline Period & Annual TFP \\
\hline $1998-2005^{\mathrm{a}}$ & 1.89 \\
\hline $1990-2005^{\mathrm{a}}$ & 3.06 \\
\hline $1996-2003^{\mathrm{a} b}$ & 0.6 \\
\hline $2003-2005^{\mathrm{a}} \mathrm{b}$ & 1.74 \\
\hline $1996-2000^{c}$ & 0.2 \\
\hline $2000-2003^{\mathrm{c}}$ & -0.1 \\
\hline $1998-2005^{\mathrm{d}}$ & 1.77 \\
\hline $1998-2005^{\mathrm{e}}$ & 0.66 \\
\hline $2000-2008^{\mathrm{f}}$ & 1 \\
\hline
\end{tabular}

Source: Prepared by the authors, on the basis of R. Fuentes, M. Larraín and K. Schmidt-Hebbel, "Sources of growth and behavior of TFP in Chile", Cuadernos de Economía, vol. 43, No. 127, Santiago, Pontificia Universidad Católica de Chile, 2006; R. Vergara and R. Rivero, "Productividad sectorial en Chile 1986-2001", Cuadernos de Economía, vol. 43, No. 127, Santiago, Pontificia Universidad Católica de Chile, 2006; R. Fuentes and M. Morales, "On the measurement of total factor productivity: a latent variable approach", Macroeconomic Dynamics, vol. 15, No. 2, Cambridge University Press, 2011; and I. Magendzo, Evolución de la productividad total de los factores, Santiago, Adolfo Ibáñez University, 2013.

a Fuentes, Larraín and Schmidt-Hebbel (2006).

b The authors do not provide information on TFP growth in these periods, but annual TFP indices which were used as a basis for calculating the data shown in the table. Specifically, the TFP index was used, with capital and employment corrected for hours of work and wages, respectively.

c Vergara and Rivero (2006).

d Fuentes R. and M. Morales (2011), on the basis of growth accounting.

e Ibid, using a state-space model.

f I. Magendzo (2013), Adolfo Ibáñez University.

The figures for 1996-2003 presented in table 4 are similar to the TFP results for those same years calculated by Fuentes, Larraín and Schmidt-Hebbel $(2006)$. This similarity occurs in two dimensions, since the annual growth of TFP in this period was $0.6 \%$, while its contribution to the overall growth of the economy was $18.92 \%$.

To clarify the source of the change in TFP, Table 6 presents the decomposition performed in equation (5). The first row of column 1 shows the difference between productivity in 1996-2003 and in 2003-2010. The value is broken down in the next three columns. The second row reports the share of each component in the change. Most of what occurred between the two periods analysed is due to the variation of intrasectoral and intersectoral productivity, the total of which represents approximately $80 \%$ of the change.

Table 6

Decomposition of TFP

\begin{tabular}{lcccc}
\hline & $\begin{array}{c}\text { Changes in sectoral } \\
\text { demand (1) } \\
\pi S \Delta B\end{array}$ & $\begin{array}{c}\text { Changes in the } \\
\text { interaction between } \\
\text { sectors (2) } \\
\pi S \Delta B\end{array}$ & $\begin{array}{c}\text { Changes in the TFT } \\
\text { of each sector (3) } \\
\pi S \Delta B\end{array}$ & $\begin{array}{c}\text { Total } \\
(1)+(2)+(3)\end{array}$ \\
\hline$\Delta \rho=0.065-0.0495$ & 0.001344 & 0.003134 & 0.002474 & 0.006949 \\
\hline Percentage & $19.34 \%$ & $45.1 \%$ & $35.6 \%$ & $100.06 \%^{\mathrm{a}}$ \\
\hline
\end{tabular}

Source: Prepared by the authors.

a The amount exceeds $100 \%$ owing to second-order approximation errors.

Table 7 shows the decomposition of 35.6\% of the observed change in TFP for the economy as a whole. The second column shows the values of $w=S \beta$, which is a vector of 12 sectors. As the vector $\beta$ can be interpreted as the distribution of the expenditure of all sectors of the economy expressed in a monetary unit, position $i$ of the vector $w(i)$ represents the increase in economic activity 
of sector $i$, measured in terms of the price of the good it produces when aggregate demand in the economy increases by one unit. The vector can thus be interpreted as a measure of the backward linkages of each sector generated by a one-unit increase in aggregate demand. These linkages can increase either because the price of the good of one sector rises relative to the price of the goods of all the other sectors, or because there is actually a technological change that raises the sectoral technical multiplier. Table 7 shows the manufacturing industry as having the largest backward linkages measured in monetary terms, followed by the commerce, hotels and restaurants sector. The third column reports the technological change in each sector, which shows that the electricity, gas and water sector registered the largest increase in productivity, followed by fishing, and financial intermediation and business services.

Lastly, the fourth column reports the result of the combined effects. This shows that four sectors contributed positively and by amounts similar to the change: electricity, gas and water; financial intermediation and business services; housing services; and manufacturing industry. The personal services and construction sectors contributed more negatively to technological change.

Table 7

Analysis of $35.6 \%$ of the change

\begin{tabular}{lccc}
\hline Sector & $\begin{array}{c}W=S B \\
(1)\end{array}$ & $\begin{array}{c}\Delta \pi \\
(2)\end{array}$ & $(1)^{\star}(2)$ \\
\hline Agriculture-forestry & 0.1042 & -0.0033 & -0.00034 \\
\hline Fishing & 0.0196 & 0.0373 & 0.00073 \\
\hline Mining & 0.1218 & 0.0075 & 0.00091 \\
\hline Manufacturing industry & 0.3466 & 0.0066 & 0.00229 \\
\hline Electricity, gas and water & 0.0828 & 0.04 & 0.00331 \\
\hline Construction & 0.1078 & -0.0264 & -0.00285 \\
\hline Commerce, hotels and restaurants & 0.2138 & 0.0009 & 0.00019 \\
\hline Transport and communications & 0.1406 & -0.009 & -0.00127 \\
\hline Financial intermediation and business services & 0.1146 & 0.0278 & 0.00319 \\
\hline Housing services & 0.2003 & 0.0149 & 0.00298 \\
\hline Personal services & 0.2096 & -0.0255 & -0.00534 \\
\hline Public administration & 0.0618 & -0.0216 & -0.00133 \\
\hline Total effect of changes in the intra-sectoral TFP & & & 0.00247 \\
\hline
\end{tabular}

Source: Prepared by the authors.

The other important component of the change in TFP is analysed in table 8. Using the same method as in the previous calculation, the composition of the term $\pi \Delta S \beta$ is analysed, broken down into two parts. First, the $(12 \times 1)$ intermediate vector $z=\pi \Delta S$ was analysed, consisting of the sectoral TFP vector, $\pi$, and the matrix of changes in the linkages, $\Delta S$. Each element $\Delta s_{i, j}$ represents monetary effect on $i$ of the change in backward linkages from sector $j$, as a result of the production of an additional unit of $j$ to satisfy demand. If $\Delta s_{i, j}<0,\left(\Delta s_{i, j}>0\right)$, in the new period, sector $j$ would be less (or more) important for sector $i$. Column $\Delta s_{, j}$ indicates the change caused by sector $j$ on the entire productive fabric, measured with the monetary multipliers. With this information, $z(i)$ can be interpreted as the dissemination of the technological changes in all sectors, and hence in sector $i$, as a result of changes in the multipliers. The larger is $z(i)$, the more important will be the technological effect disseminated by sector $i$. 
Table 8

Analysis of $45.1 \%$ of the change in TFP

\begin{tabular}{lccc}
\hline Sector & $\begin{array}{c}z=\pi \Delta S \\
(1)\end{array}$ & $\begin{array}{c}B \\
(2)\end{array}$ & $(1)^{\star}(2)$ \\
\hline Agriculture-forestry & 0.0059 & 0.0351 & 0.00021 \\
\hline Fishing & 0.0209 & 0.0033 & 0.00007 \\
\hline Mining & 0.0044 & 0.0824 & 0.00036 \\
\hline Manufacturing industry & 0.0099 & 0.0963 & 0.00095 \\
\hline Electricity, gas and water & 0.0278 & 0.0179 & 0.00050 \\
\hline Construction & -0.0008 & 0.0933 & -0.00007 \\
\hline Commerce, hotels and restaurants & -0.0044 & 0.1376 & -0.00061 \\
\hline Transport and communications & 0.0031 & 0.0603 & 0.00019 \\
\hline Financial intermediation and business services & 0.006 & 0.027 & 0.00016 \\
\hline Housing services & 0.0037 & 0.2003 & 0.00074 \\
\hline Personal services & 0.0041 & 0.1872 & 0.00077 \\
\hline Public administration & -0.0021 & 0.0592 & -0.00012 \\
\hline Total effect of changes in the intra-sectoral TFP & & & 0.00314 \\
\hline
\end{tabular}

Source: Prepared by the authors.

The fourth column of Table 8 can be interpreted as the technological progress spread throughout the production system, with technology and consumer preferences held constant.

The manufacturing sector disseminates the most technological progress throughout the production system, followed by housing services and personal services. Apparently, the construction, public administration, and commerce, hotels and restaurants sectors saw their influence on the productive fabric decline, so the effects of their interaction with the other sectors also diminished.

The effects of the two key components of the decomposition are illustrated in diagram 1. The horizontal axis shows the intrasectoral effects of each sector on TFP, while the vertical axis shows the intersectoral diffusion effects. From these two dimensions, four categories are can be distinguished: quadrant I groups the sectors in which both TFP and the effects of technological linkages increased. In these sectors, not only is there an improvement in the technologies used, but they also spread across the economy. Quadrant II contains sectors in which TFP declined, but the intensity of cross-sectoral linkages increased. For this reason, it is possible that they act as constraints on technological growth, because their low productivity diffuses throughout the productive system. Quadrant III consists of sectors with a negative TFP, but their effects throughout the economy were small, so they do not restrain productivity growth. Lastly, quadrant IV includes the sectors in which sector productivity increased, but whose effects on the rest of the economy were weak, so they need to be more integrated into the economic system.

Four of the sectors in quadrant I stand out for their productivity growth and its effects on the productive system: manufacturing industry; housing services; ${ }^{8}$ electricity, gas and water; and financial intermediation and business services. These are followed with weaker effects by the mining sector.

8 According to the definition provided by the Central Bank of Chile, the housing services sector encompasses the services provided by homes used for residential purposes. In practice, the production account of this activity records the value of the rent paid by tenants and the imputed rental value of owner-occupied housing. This sector represents a large share of final demand. Any increase in its productivity is basically due to an increase in value-added, which is calculated as a proportion of the net value of the housing stock. Accordingly, the information provided by this sector should be used with caution when calculating its effect on productivity. 
Diagram 1

TFP: intersectoral and intrasectoral effects

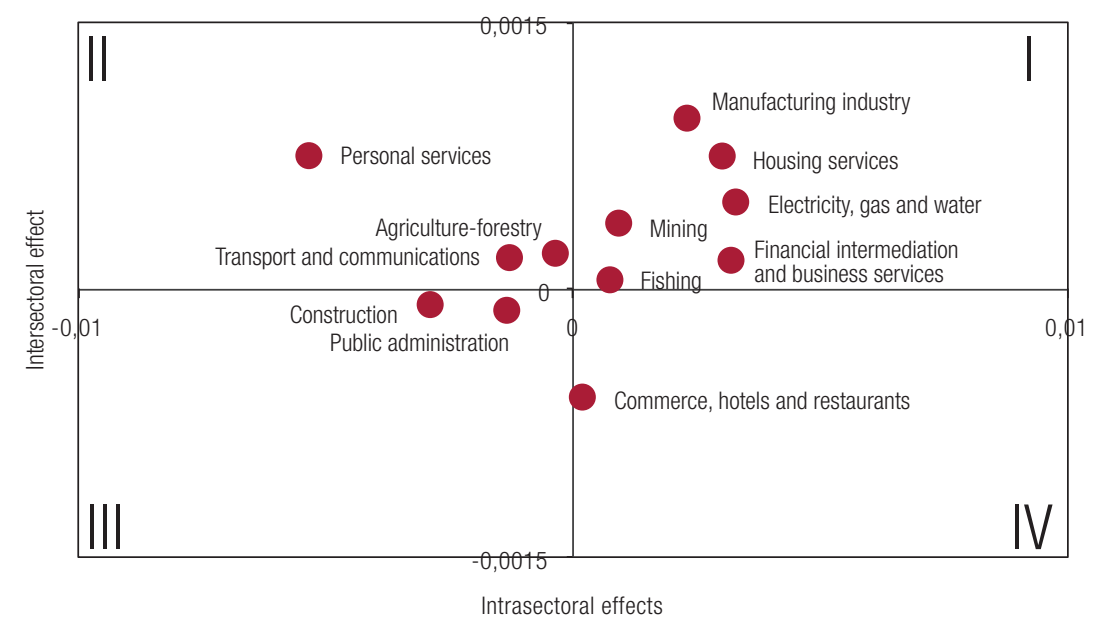

Source: Prepared by the authors.

Quadrant II is dominated by the personal services sector, which encompasses education, health, social service activities and associations, leisure activities, waste management and a wide range of services, including washing and cleaning of textile and fur products, hairdressing services, funeral services, domestic service and others. These are mainly services provided to households.

Quadrant III contains two sectors: construction and public administration. The change in the effect of the first of these on the productive fabric is small, and it also displays a considerable reduction in TFP.

Quadrant IV comprises the commerce, hotels and restaurants sector, which displays a very small increase in productivity, along with a substantial reduction in its effect on the economy.

\section{Discussion}

The results presented so far require two clarifications before offering conclusions. On the one hand, the intensity of the change in productivity should be discussed, and on the other hand a hypothetical analysis of its causes will be presented.

The intensity of change is reflected in the result of the calculation made on the basis of equation (4):

$$
\Delta \rho=\rho_{03,10}-\rho_{96,03}=0,0565-0,0495=0,007=0,7 \%
$$

where $\rho_{03,10}$ and $\rho_{96,03}$ represent TFP calculated for the periods 2003-2010 and 1996-2003, respectively. The result shows that productivity grew by $0.7 \%$ between the two periods, with the increase in efficiency occurring in 2003-2010, when GDP growth was higher than in 1996-2003 (see table 4). Consequently, the relative share of the increase in efficiency was smaller in the second period than in the first. These conclusions confirm the note of caution expressed by Fuentes, Larrain and Schmidt-Hebbel (2006) concerning the scant economic growth attributable to the "inspiration" factor in their analysis of Chilean growth accounting.

There are two, not necessarily mutually exclusive, hypotheses explaining the reported changes in TFP. According to the first, and given the procyclicality attributed to TFP by Fuentes, Larraín and Schmidt-Hebbel (2006), the years selected for preparing the input-output tables used in this study 
and the characteristics of the business cycle in Chile (see figure 1), the absolute increase in TFP may have been driven by cyclical factors such as the terms-of-trade improvement induced by the rise in the copper price during the period analyzed (see Fuentes, Larraín and Schmidt-Hebbel, 2006). This first hypothesis, of a macroeconomic type, is complemented by a microeconomic one, relating to a specific transmission channel that may have helped sustain the level of TFP.

The second hypothesis stems from the intersection between the sectoral decomposition performed in this study and summarized in diagram 1, on the one hand, and the results reported by Fernandes and Paunov (2012), on the other. The synthesis presented in this diagram shows the positive influence exerted on productivity growth by the manufacturing; electricity, gas and water; and financial intermediation and business service sectors. In contrast, the Fernandes and Paunov study links these three sectors to the substantial increase in foreign direct investment (FDI) in the services sector during the period analysed. In the 1990s, the services sector absorbed roughly $60 \%$ of FDI in Chile, which, through price reduction mechanisms, quality improvements, accentuation of diversification and knowledge dissemination, boosted the TFP of firms in the manufacturing sector.

\section{Conclusion}

The present study set out to analyse the sectoral composition of changes in TFP occurring in Chile from 1996 to 2010, within the Solow growth accounting framework and taking intrasectoral interaction into account. This exercise made use of input-output tables for the years 1996, 2003 and 2010 provided by the Central Bank of Chile. Part II describes the decomposition method used, while section III and the annex describe the calculations performed to obtain the basic data; and section IV analyses the results obtained.

The decomposition of TFP was performed in three stages, namely intrasectoral productivity, its diffusion effects, and changes in demand that influence productivity. It was found that over $80 \%$ of the change in productivity in the period analyzed was due to the first two factors.

The results of this research make it possible to construct a taxonomy of sectors, based on their capacity to drive the economy and changes in sectoral productivity growth. This taxonomy identifies manufacturing industry, and the electricity-gas-water, and financial intermediation and business services sectors, as the drivers of TFP growth in 1996-2010. Productivity growth in these sectors spread throughout the production fabric.

By recording a decline in productivity during the period, which exerted a major influence on the productive system, the personal services sector may have restricted productivity growth in the economy at large.

\section{Bibliography}

Álvarez, R. and R. Fuentes (2009), "Labour market regulations and productivity: evidence from Chilean manufacturing plants", Working Paper, No. 396, Santiago, Pontificia Universidad Católica de Chile.

(2004), "Patrones de especialización y crecimiento sectorial en Chile", Working Paper, No. 288, Santiago, Central Bank of Chile.

Baumol, W.J. and E.N. Wolff (1984), "On interindustry differences in absolute productivity", Journal of Political Economy, vol. 92, No. 6, Chicago, The University of Chicago Press.

Bergoeing, R., A. Hernando and A. Repetto (2005), "Market reforms and efficiency gains in Chile", Working Papers, No. 372, Santiago, Central Bank of Chile.

Chumacero, R.A. and R. Fuentes (2006), "Chilean growth dynamics", Economic Modelling, vol. 23, No. 2, Amsterdam, Elsevier. 
Del Gatto, M., A. Di Liberto and C. Petraglia (2011), "Measuring productivity", Journal of Economic Surveys, vol. 25, No. 5, Wiley.

Easterly, W. and R. Levine (2002), "It's not factor accumulation: stylized facts and growth models", Economic Growth: Sources, Trends, and Cycles, N. Loayza, R. Soto and K. Schmidt-Hebbel (eds.), Santiago, Central Bank of Chile.

Fernandes, A.M. and C. Paunov (2012), "Foreign direct investment in services and manufacturing productivity: evidence for Chile", Journal of Development Economics, vol. 97, No. 2, Amsterdam, Elsevier.

Fuentes, R. (2011), "Una mirada desagregada del deterioro de la productividad en Chile: ¿existe un cambio estructural?, Working Paper, No. 401, Santiago, Pontificia Universidad Católica de Chile.

Fuentes, R. and M. Morales (2011), "On the measurement of total factor productivity: a latent variable approach", Macroeconomic Dynamics, vol. 15, No. 2, Cambridge University Press.

Fuentes, R., M. Larraín and K. Schmidt-Hebbel (2006), "Sources of growth and behavior of TFP in Chile", Cuadernos de Economía, vol. 43, No. 127, Santiago, Pontificia Universidad Católica de Chile.

Harberger, A.C. (1998), "A vision of the growth process", American Economic Review, vol. 88, No. 1, Nashville, Tennessee, American Economic Association.

Henríquez, C. (2008), "Stock de capital en Chile (1985-2005): metodología y resultados", Studies in Economic Statistics, No. 63, Santiago, Central Bank of Chile.

Hodrick, R.J. and E.C. Prescott (1981), "Postwar U.S. business cycles: an empirical investigation", Discussion Papers, No. 451, Northwestern University.

Magendzo, I. (2013), Evolución de la productividad total de los factores, Santiago, Adolfo lbáñez University.

Miller, R. and P.D. Blair (2009), Input-output Analysis: Foundations and Extensions, New York, Cambridge University Press.

OECD (Organization for Economic Cooperation and Development) (2009), Measuring Capital. OECD Manual, Paris.

(2001), Measuring Productivity. Measurement of Aggregate and Industry-level Productivity Growth, Paris.

Pavcnik, N. (2002), "Trade liberalization, exit, and productivity improvements: evidence from Chilean plants", Review of Economic Studies, vol. 69, No. 1, Oxford University Press.

Prescott, C.E. (1998), "Needed: a theory of total factor productivity", International Economic Review, vol. 39, No. 3.

Solow, R.M. (1957), "Technical change and the aggregate production function", Review of Economics and Statistics, vol. 39, No. 3.

Timmer, M.P. and others (2010), Economic Growth in Europe. A Comparative Industry Perspective, Cambridge University Press.

United Nations (2009), System of National Accounts 2008, New York, European Commission/International Monetary Fund/Organization for Economic Cooperation and Development/United Nations.

Vergara, R. and R. Rivero (2006), "Productividad sectorial en Chile 1986-2001", Cuadernos de Economía, vol. 43, No. 127, Santiago, Pontificia Universidad Católica de Chile.

Wolff, E.N. (1985), "Industrial composition, interindustry effects, and the U.S. productivity slowdown", The Review of Economics and Statistics, vol. 67, No. 2, Cambridge, Massachusetts, The MIT Press. (1984), "Industrial composition, interindustry effects, and the U.S. productivity slowdown", Economic Research Reports, No. 84-09, New York, New York University. 


\section{Annex A1}

\section{Data and calculation methods used}

This annex describes the calculations performed using the three methods indicated.

\section{Calculation of the technical coefficients}

The data provided by the Central Bank of Chile are grouped into production-and-use matrices (see Miller and Blair, 2009), and these were the main source used for calculating the intersectoral transaction matrices.

The Miller and Blair (2009) industry-demand driven model was used, in which technology is determined by the production structure for goods, irrespective of the industry from which they originate, to develop the total requirement matrices. In analytical terms,

$U$ : matrix of uses -13 products by 12 sectors.

$V$ : matrix of sectoral production -12 sectors by 13 products

$s=V^{*} i$ : industrial or sectoral production vector $(12 \times 1)$

$Q=V^{*} i$ : commodities production vector $(13 \times 1)$

For simplicity, time subscripts were not used.

On the basis of this information, the intersectoral transactions matrix was calculated as follows:

$$
\begin{aligned}
& B=U \cdot \hat{s}^{-1} \\
& D=V \cdot \hat{q}^{-1} \\
& Z=D \cdot B \cdot \hat{s}
\end{aligned}
$$

In this case, a circumflex is placed on the vectors (for example, $\hat{s}$ ) to indicate its diagonalization. The national purchase and import matrices were added together to calculate the coefficients matrix A. Accordingly, the following information, also provided by the Central Bank of Chile, is added to the calculated transaction matrix:

M: matrix of imports by each sector (12x12)

$L_{v}$ : row vector representing the value added of the wage by sector $(12 \times 1)$

$K_{v}$ : row vector representing the value added by capital by sector (12x1)

$t_{v}$ : row vector of indirect taxes $(12 \times 1)$

The column vector of the total production is calculated as follows:

$$
x=i^{\prime} Z+i^{\prime} M+l_{v}+k_{v}+t_{v}
$$

To calculate the column vector of final demand, the products of each sector are identified and the corresponding intermediate sales are subtracted.

$$
y=x-i^{\prime} Z^{\prime}-i^{\prime} M^{\prime}
$$




\section{Calculation of the sector productivity vector}

Since productivity is calculated for different periods, the approximation proposed by Wolff (1984) is used, as follows:

$$
\begin{aligned}
\beta_{i} & =\frac{y_{i}}{Y} \\
v_{L} & =\frac{w L}{Y} \\
v_{k} & =\frac{r K}{Y}
\end{aligned}
$$

The average values of two periods are represented as follows:

$$
\bar{\beta}_{i}=\frac{\beta_{i, t}+\beta_{i, t+1}}{2}
$$

The approximate value of aggregate TFP can be calculated by the following equation:

$$
\rho \cong \sum_{j} \bar{\beta}_{j} \Delta \log y_{j}-\bar{v}_{L} \Delta \log L-\bar{v}_{K} \Delta \log K
$$

The approximate value of TFP in sector $j$ is calculated in a similar way:

$$
\pi_{j} \cong-\left(\sum_{i} \bar{\alpha}_{i, j}\left(\Delta \log a_{i, j}\right)-\bar{v}_{L, j}\left(\Delta \log l_{j}\right)-\bar{v}_{K, j}\left(\Delta \log k_{j}\right)\right)
$$

where $\alpha_{i, j}=\frac{p_{i} a_{i, j}}{p_{j}}, v_{L, j}=\frac{w l_{j}}{p_{j}}, v_{K, j}=\frac{r k_{j}}{p_{j}}$. The dash placed above the variables signifies that the Turnquist-Divisia index weights were used for several periods. 